\title{
Los Derechos Fundamentales del Trabajo en el Marco de las Reformas del Nuevo Orden Económico
}

\author{
Jorge Rosenbaum Rimolo
}

Resumo: Anova ordem econômica intemacional atua sobre as relacõoes de trabalho, ao mesmo tempo em que 0 quadro normativo da regulamentação trabalhista passa por intenso processo de desreegulamentação e flexibilização. A perda de centralidade no trabalho subordinado constitui um fenômeno próprio de um sistema econômico que destrói maispostosde trabalho do que gera, fazendo com que, no arquétipo da sociedadecontemporânea, seinstaleo fenômeno da crescente exclusão de pessoas, que permanecem à margem de muitos direitos básicos, eque perdem a identidade de sua cidadania civil. Aimportância queassumem os diritos fundamentais do trabalho tem propiciado o surgimento de novas propostas, algumas das quais começam a se desenvolver em nível das relaçoes intemacionais. Tais propostas contemplam a possivel re regulamentação do direitos fundamentais do trabalho, estabelecendo nomas trabalhistas mínimas, em âmbito supranacional. Esteartigo avalia duaspossibilidadesinovadoras: a primeira, resultanteda Declaração dos Diritos Fundamentais do Trabalho, sob a ótica da OIT e da Carta Sociolaboral do Mercosul, ambas de 1998; a segunda, emanada da instituição de cláusulas sociais entre as regras multilaterais do comércio intemacional.

Palavras-Chave: DireitosFundamentais, Desemprego, Declaração dos DireitosFundamentaisdo Trabalho da OIT, Carta Sociolaboral do Mercosul.

Resumen: El nuevo orden económico intemacional actía sobrelas relaciones de trabajo, al tiempo queel cuadro nomativo dela regulación laboral enfrenta intensosprocesos dedesregulación yflexibilización. La pérdida decentralidad del trabajo subordinado constituye un fenómeno propio de un sistema económico que destruye más puestos laborales que los que genera, provocando que en el arquetipo de sociedad contemporánea aparezan fenómenos de creciente exclusión depersonas, lasquepermanecen marginadasdemuchosderechoshásicosypierden laidentidaddesu ciudadania civil. La importancia que asumen los derechos laborales fundamentales, ha promovido el surgimiento denuevas propuestas, algunas de las cuales han comenzado a devenvolverse a nivel de las relaciones intemacionales. Las mismas postulan la posible «re reglamentación» de los derechos fundamentales del trabajo, acordándose nomas laborales minimasen el ámbito supranacional. En esteartículo se examinan dosproyeccionesrenovadoras: la primera, resultantedela Declaración sobrelos derechosfundamentales del trabajo en el seno dela OIT y dela Carta Sociolaboral para el Mercosur(ambasde1998); la segunda, emanada dela instrumentación decláusulassocialesentrelasreglasmultilaterales del comercio intemacional.

Palabras-clave: Derechos Fundamentales, Desempleo, Declaración de Derechos Fundamentales des Trabajo de OIT, Carta Sociolaboral del Mercosur.

${ }^{*}$ Profesor de Derecho del Trabajo y de la Seguridad Social de la Facultad de Derecho del la Universidad de la República, Montevideo, Uruguay. E-mail: jrosen@ adinet.com.uy. 


\section{Un nuevo orden económico}

El telón de fondo sobre el que proyectaremos al gunas reflexiones relativas a los derechosfundamentales del trabajo, respondeal advenimiento de un nuevo orden económico, que se ha impuesto en forma predominante y casi hegemónica a nivel mundial. Ese nuevo orden responde a las profundas transformaciones que han sacudido y continúan sacudiendo el escenario económico planetario, alterando las raíces del mundo productivo, del comercio internacional, del mercado de trabajo y de las relaciones laborales.

Constituye un dato objetivo advertir que desde mediados de los años 70 en adelante, el contexto universal fue modificándose y que más concretamente en la década de los 90 se produjo una aceleración de los efectos implicados por diferentes factores, entre los que cobra especial relieve la gl obalización.

La misma representa, en lo esencial, una expansión y profundización de la economía capitalista, que implica la liberación de espacios muy amplios para facilitar los movimientos internacionales de capital es y de la inversión (en sus proyecciones financieras) y la transnacionalización en la actividad económica (fundamentalmente, en sus proyecciones comerciales y productivas), cuyo alcance pretende ser entonces mundial.

La liberalización del comercio que se constituye en uno de los objetivos caracterizantes de esta era, a la vez que impone una apertura de fronteras a los Estados nacionales (ampliando los mercados, facilitando las exportaciones y eliminando las barreras arancelarias, los derechos compensatorios y otras modalidades de proteccionismo), propicia paralelamente el surgimiento de otro fenómeno, el de la integración de muchos de ellos en torno a grandes bloques económicos y comerciales de alcance intra regional einternacional, en los que los países asociados procuran complementar y acrecentar sus potencialidades.

Todo ello confluye hacia una progresiva expansión dela eliminación delasfronteras nacionales a través de la libre circulación de bienes, servicios y personas entre los distintos países, lo que ha llevado a algunos analistas a vaticinar el propio fin a los Estados-naciones, con la consecuente muerte de la política.

Por otra parte, debe señalarse que el proceso de globalización o mundialización, se ha visto facilitado ampliamente por la incorporación de nuevas tecnologías, que transforman los paradigmas tecnológicos organizacionales.

Se trata, pues, de una revolución industrial, con grados de renovación continua y permanente, caracterizada por progresos técnicos cada día más sofisticados, removedores y utilitarios, que impactan en sectores claves de la producción y en la infraestructura organizativa que la respalda. Una revolución del conocimiento a través del cual se va generando la propiedad de un know-how cuyo valor se concentra en los paísescentrales dela economía mundial, promoviendo una vertiginosa automatización 
y robotización de los procesos productivos, haciendo desaparecer industrias y tecnologías que van quedando obsoletas, volviendo innecesarias numerosas tareas y procesos y, fundamental mente, en lo que a nuestro interés de análisis concierne, eliminando puestos de trabajo en una progresión geométrica incontrolable.

El mundo del trabajo se ha visto estremecido en la última década, siendo posible sostener que enfrentamos el advenimiento de un sistema económico que destruye más puestos de trabajo que losque genera. Los mayores y más graves problemas del mercado de trabajo de nuestra época se están generando por la sustitución de mano de obra por tecnología, la posibilidad técnica de producir con menos mano de obra e, incluso, hasta por la conveniencia de mantener un desempleo funcional.

El crecimiento económico (p. ej., del PBI), cuando existe, es un crecimiento sin nuevos trabajos (jobless growth), que viene a corroborar la premonición que un gran juslaboralista recientemente desaparecido, el Profesor M anuel Alonso O lea (C atedrático de $D$ erecho del Trabajo de la U niversidad Complutense de M adrid) vaticinara en los años 80 bajo el memorable título de uno de sus ensayos: "El trabajo como un bien escaso".

\section{El papel del Derecho del Trabajo}

Pensamos que en este contexto descriptivo de la realidad presente, se hace necesario reflexionar sobreel papel quelecorresponde desempeñar al D erecho del Trabajo, como una de tantas "multi" disciplinas a través de las cual es se estudia y analiza el fenómeno de las relaciones laborales que interactúan en el mundo del trabajo.

Precisamente, recordemosque el $D$ erecho del Trabajo siempreha oscilado entrelo económico y lo social, y ello es así porque su esencia se muestra estructuralmente proclive al compromiso (Barbagelata 1985:19).

En el esquema clásico que lo vio nacer, los cimientos del Derecho Laboral se fueron estructurando en torno a un paradigma central: el trabajo asalariado de un universo (sin duda mayoritario) de la población trabajadora. Su figura contractual típica (el contrato de trabajo) supone la configuración de una relación de empleo por tiempo indeterminado, en la que el trabajador posee una categoría preestablecida acorde a un oficio, profesión o actividad y es remunerado con un salario predominantemente fijo. Esa relación de trabajo se desenvuelve en un contexto en el que predominan las organizaciones del modelo keynesiano-fordista, siendo la «gran fábrica» y la «gran oficina», los "centros" de dominio de la producción industrial, del comercio y la distribución de bienes y de la prestación de servicios y, por lo tanto, quienes asumen visiblemente el rol de sujeto empleador. 
Asistimos a un arquetipo de Sociedad en la cual las personas (la PEA de un país) procuran y encuentran un "empleo", que les asegura su derecho fundamental al trabajo. La empleabilidad se convierte, en consecuencia, en un elemento de inclusión del individuo a la sociedad 0 , si se prefiere, en un factor de ciudadanía laboral y social.

\section{La pérdida de centralidad del trabajo asalariado y la flexibilización laboral}

El panorama contemporáneo indica que progresivamente comienza a verificarse una pérdida de centralidad del trabajo subordinado y que al rededor de la nueva organización de la empresa proliferan otras formas de prestación de actividades en las que se desdibujan los indicios de la dependencia laboral de sus prestadores y se difumina la «responsabilidad laboral» de quien constituye el destinatario final de las mismas.

D e allí que se plantee como interrogante si estos fenómenos representan un retorno del $\mathrm{D}$ erecho del Trabajo al tronco originario del D erecho Civil del cual, en el pasado y según la opinión de una mayoría de la doctrina, aquél se habría desgajado, por efecto de un proceso de progresiva «deslaboralización» del trabajo que prestan numerosas personas. Cobran singularidad muchas delas figuras contractuales atípicas, en un contexto también muy diferente, en el que se origina y desarrollan procesos de flexibilización a los efectos de posibilitar la transformación de la estructura organizacional de la empresa y la propia organización del trabajo en la empresa.

Los nuevos requerimientos productivos son los que impulsan a flexibilizar. En ello inciden múltiples factores, como la competitividad, los costos, la inversión en tecnología, la productividad, la maximización de las ganancias.

Su surgimiento coincide con (o provoca) un cambio de la propia cultura empresarial, que se traduce incluso en una ofensiva ideológica en torno a la necesidad de contar con «una fuerza de trabajo flexible» para la nueva empresa que Tofler ha calificado, precisamente, como "la empresa flexible" (1990).

Tal como lo señalan algunos autores, mientras que en el discurso anterior sobre los derechos ciudadanos, se hablaba de "trabajo digno", la nueva ideología neoliberal introduce el concepto de "bien" (uno más de los que se transan en el mercado y está sujeto a los máximos beneficios) (Bonetto y Piñero 2000: 64).

Y ello, pese a contradecir uno de los axiomas fundamentales de la C onstitución de la O IT: "el trabajo no es una mercancía, cuya consagración como principio ha sido resaltada por el Profesor M ario Grandi (1997: 189).

Parafraseando a M ario Ackerman, debe establecerse que "si son recursos, no son humanos". Sin embargo, resulta curioso que las nuevas técnicas degestión del personal incorporen el factor humano como una pieza dave de la competitividad de la 
empresa, ya que los nuevos empleados deben estar dispuestos a trabajar para la calidad. De allí las exigencias de polivalencia, trabajo en equipo, capacitación y recalificación profesional creciente, gestión participativa del personal, búsqueda dela excelencia, etc.

Todo esto hallevado a pensar a algunosanalistas, queexisteuna clara consustancialidad entreesos dos fenómenos: la globalización y la flexibilización. Ambos parecen necesitarse mutuamente y en ese orden, la flexibilidad «ha sufrido un proceso de subsunción», pasando a ser un instrumento funcional y operativo para facilitar laglobalización, queseha convertido en un fin, en el objetivo o la meta final que la economía, el comercio y el capital procuran alcanzar (Belzunegui Eraso 2002: 98).

El arquetipo de Sociedad también se transforma y resulta diferente, porque ni el trabajo autónomo, ni latercerización o descentralización productiva, ni el trabajo precario, ni el trabajo informal, logran absorber la mano de obra disponible. La oferta de trabajo de prestaciones de actividad resulta insatisfecha y no permite a los individuos costear su propia subsistencia o la de quienes dependen de su ingreso par subsistir.

En suma, asistimos al desenvolvimiento de una Sociedad que comienza a excluir individuos, marginándolos de toda clase de derechos y vaciando -en consecuenciasu ciudadanía.

En nuestra opinión, másqueun futuro sin trabajo (como el que anunciara Rifkin), habremos de abordar un futuro en el que continuará existiendo el trabajo subordinado y quizás, como figura central de las modalidades de prestación de actividades, pero para cada vez para menos personas, con mayor desigual dad y menor seguridad. En el mundo del trabajo y de la producción se habrá de ahondar la brecha entre los llamados "insiders" (es decir, trabajadores subordinados "tradicionales" o simples prestadores desestructurados de actividades) y los "outsiders" (personas impedidas de acceder a un trabajo, cualquiera sea éste: precario, tercerizado, informal, etc.).

La nueva "cultura" dela flexibilización busca eliminar losobstáculosquese presentan en su camino y entre ellos tiende a modificar la estructura del ordenamiento jurídico laboral «clásico», facilitando un proceso de adaptabilidad a los requerimientos y exigencias del nuevo modelo productivo y organizacional, especialmente en lo que concierne a la organización del trabajo. Y ello ocurre porque así lo exige el mercado (capitalista), frente a una realidad globalizada.

En semejante realidad compleja, aparecen numerosos los ejemplos de legislaciones comparadas que han apelado a reformas laborales, aplicando técnicas jurídicas de desregulación y flexibilización, queallanan la introducción de prácticas de adaptabilidad en materias tales como la contratación laboral, la gestión del tiempo de trabajo, la organización y rendimiento del trabajo, la variabilidad de los salarios según la situación económica de la empresa, la facilitación del despido de trabajadores y la 
eliminación o reducción de costes fiscales y sociales, entre las más importantes dimensiones que exhibe el fenómeno.

En términos generales, puede señalarse que se trata de respuestas dadas ante fuertes demandas de las nuevas estrategias que dominan la economía y afectan la estructura social.

Pero interesa interrogarse por qué el concepto de flexibilidad ha pasado a ocupar un lugar preeminente en el debate sobre el marcado de trabajo. Creemos que lo ha hecho para resaltar la "supuesta" disfuncionalidad de las prácticas reguladoras del mismo.

En efecto; las "reglas del mercado" determinan que, en la medida que es deseable generar más empleo, promover la inversión y aumentar la competitividad de la empresa, o incluso desarrollar polos locales o regionales de producción, se torna imprescindible-de acuerdo a la ideología del modelo económico predominante y hegemónico- remover las normas que instauraron la protección laboral tradicional, consideradas como excesos demagógicos y antieconómicos de la legislación social.

Se verifica un proceso que apela a diferentes vías, entre las cuales se destacan:

a) la eliminación o supresión de las normas que regulan las relaciones de trabajo (desregulación muchas veces "salvaje”) paraqueel mercado seencarguede establecer libremente las reglas de los temas desregulados;

b) la disminución, el aligeramiento o la adaptación dela ordenación normativalaboral (flexibilización), principalmente la que posee carácter heterónomo y es dictada por el Estado;

c) la disponibilidad de derechos laborales en el plano colectivo, deforma que a través de la negociación colectiva, se permiten ciertos apartamientos flexibilizadores respecto de las soluciones garantistas que consagra la ley, que no es derogada. En todo caso, la ley semantiene como un cerrojo de seguridad, queopera de reaseguro de los derechos de los trabajadores. En esta opción, lo que se impide (o no se legitima) es que las partes del contrato individual puedan desplazar la solución legal para desmejorarla. Setrata demodalidades deflexibilidad deadaptación, queimplican la posibilidad de celebrar colectivamente acuerdos derogatorios que pueden resultar, incluso, menos favorables quelas previsiones contenidas en la ley. A través deella, se abrecamino unatendencia transformadora sobrela legitimación deunanegociación colectiva «in pejus». Secrea un marco dedisponibilidad autonómica muy grande, ya que se extienden las facultades de modificar el derecho estatal a través del convenio colectivo, siguiendo las pautas de valoración y el poder de negociación que poseen los sujetos colectivos (Rosenbaum 1995: 97 y sigs.). 


\section{Los derechos fundamentales del trabajo}

El nuevo orden económico internacional, en el que la globalización ocupa un espacio central y junto a ella o como consecuencia de ella, también ocurre lo mismo con la liberalización del comercio y la integración regional, plantea numerosos desafíos en el ámbito de las relaciones de trabajo. También lo plantean las transformaciones que operan sobre el ordenamiento jurídico laboral, tales como las quehan surgido de la desregulación y la flexibilización.

Este enfoque ha sido desarrollado desde una interesante óptica no jurídica por C ristina C acciamali (D irectora de PRO LAM en la U niversidad de Sao Paulo), para quien la liberalización del comercio ha actualizado el debate sobre la necesidad de promover normas mínimas de trabajo, lo que se plantea en dos campos: las relaciones comerciales internacionales y la defensa de los derechos humanos. Sin embargo, para la autora la controversia trasciende esos dos ámbitos, al incidir - por un lado en la legislación, y - por el otro - en las prácticas laborales de cada país, añadiendo nuevos valores y reglas de funcionamiento a los mercados de trabajo (2002: 91).

Q uizás algunos de estos problemas no constituyan estrictamente nuevos retos, sino por el contrario, representen el resurgimiento de viejas asechanzas, pero bajo nuevas formas de exteriorizarse. En una ponencia expuesta en el V Congreso Regional Americano de D erecho del Trabajo y de la Seguridad Social (Lima 2001), 0 scar Ermida U riarte incorporaba un subtítulo sugerente, a la vez que descriptivo: "La globalización y la nueva cuestión social".

Uno de los aspectos que consideramos trascendente es el que concierne a los derechos laborales fundamentales frente al nuevo orden económico; en torno a los mismos, han surgido novedosas propuestas en el plano internacional.

\section{Propuestas sobre la "re reglamentación internacional" de los derechos fundamentales del trabajo}

U na corriente de pensamiento se ha venido perfilando en distintos ámbitos y postula la imperiosa necesidad de establecer o acordar normas mínimas de trabajo, situando el ámbito para su generación a nivel supranacional. Se sostiene que los problemas del trabajo contemporáneo trasvasan lasfronteras y encuentran sus principales causas en las relaciones económicas, financieras, productivas y comerciales internacionales. M ás aún, es posible anotar que las nuevas estructuras productivas y de comercialización de bienesson, en la actualidad, esencialmentemultinacionales (opinión vertida por los investigadores del G rupo Pet/C apes, 1996: 122). 
Por lo tanto, se entiende que las soluciones deben provenir de aquél ámbito y dirigirse hacia una "re - regulación internacional" de los derechos laborales.

En este terreno, parece claro que existirían distintos fundamentos para justificar opciones dirigidas a materializar el camino sugerido. Sin pretender agotar su elenco, señalaremos los principales argumentos.

Por una parte, existen justificaciones éti cas, centradas en la creciente universalización de los derechos humanos fundamentales, entre los cuales los derechos laborales ocupan un espacio preeminente. Estos valores han pasado a formar parte de un estado de conciencia en la opinión pública que moviliza cada vez a más personas, movimientos, organizaciones e instituciones, incluso a niveles internacionales. Se trata de un camino que a priori pudiera considerarse muy proactivo, pero poco eficaz por la ausencia de poder real en el campo normativo, aunque progresivamente ha demostrado ser capaz de acumular el valor moral de sus puntos de vista y convicciones a través de la condena pública de situaciones concretas.

Por otra parte, existen razones político instituci onales, ya que como lo expresara el Informe del Director G eneral de la O.I.T. sobre Globalización y trabajo decente en las Américas, presentado en la XV Reunión Regional Americana, "la libertad y la democracia no son un efecto a posteriori del desarrollo, sino una condición básica para el desarrollo tanto económico como social de los países" (2002: 37).

Transcribiendo la C arta D emocrática Americana aprobada por la O EA hace un año, se recuerda que "la promoción y el fortalecimiento de la democracia requieren el ejercicio pleno y eficaz de los derechos de los trabajadores y la aplicación de normas laboral es básicas... La democracia sefortalececon el mejoramiento delas condiciones laborales y la calidad de vida de los trabajadores del hemisferio" (art. 10).

No se trata de conceptos novedosos y por otra parte, muchos temen que sólo impliquen una expresión de deseos, de valor meramente programático.

Sin embargo, lo que no puede ni debe dejarse de considerar es que la necesidad de que el Estado conceda a sus ciudadanos una seguridad y una protección básicas, más que un planteamiento ideológico, constituye una auténtica demanda planteada en el seno de cada sociedad a partir de las vivencias cotidianas de sus integrantes. Como lo recuerda el $D$ irector $G$ eneral, son absolutamente comprensibles las dudas que muchas personas tienen sobre los beneficios de la globalización y las respuestas a esas dudas las encuentran fundamentalmente en el mundo del trabajo por tratarse de la referencia que utiliza la gente para descodificar su calidad de vida.

Pero también median fundamentos de contenido económico; en efecto, la globalización persigue y necesita dar batalla, tal como ocurrió en el pasado, contra el "dumping social" en la producción y el comercio. Al menos, ese continúa siendo el interés 
de muchos de los países industrializados, tal como ocurriera en 1919 al aprobarse la Constitución de la O.I.T.

El Tratado de Versailles expresa en el Preámbulo que “... si cualquier nación no adoptare un régimen de trabajo realmente humano, esta omisión constituiría un obstáculo a los esfuerzos de otras naciones que deseen mejorar la suerte de los trabajadores en sus propios países" (tercer Considerando).

Resulta inocultable hoy día que si observamos el fenómeno con perspectiva, notaremos que en realidad parece estar procesándose una claudicación generalizada frente al dumping social como fenómeno cada vez más extendido en la práctica. M uchos países, con millones de habitantes y gran oferta de mano de obra, carentes de recursos suficientes y necesitados de divisas, compiten en el mercado internacional con lo único que pueden competir: la oferta de productos a precios inferiores, reduciendo entre otrosel costo del trabajo (a través de una estructura productiva que se sustenta en salarios ínfimos, condiciones de trabajo inadecuadas y desconocimiento de derechos mínimos, sin seguridad social, con bajísimos estándares en materia de salud, educación y acceso a la justicia, así como sin sindicatos ni negociación colectiva).

M ás aún, la experiencia ha demostrado que esas economías se tornan reservorios útiles para los intereses de corporaciones multinacionales, que aprovechan esa mano de obra disponible, deslocal izan sus establecimientos o tercerizan procesos de producción, siendo su único provecho la obtención de mayores ganancias o réditos para sus inversiones, sin interesarse en la elevación gradual de los derechos laborales de esos ciudadanos periféricos, sobreexplotados a nivel internacional. Algunas de ellas están siendo colocadas bajo sospecha y son expuestas ante el gran público consumidor de sus productos.

Sin lugar a dudas, las respuestas a estos problemas son harto difíciles de concretar a través de la instrumentación de políticas normativas adecuadas, pero trasuntan una preocupación por generar, rescatar y garantizar la observancia de los derechos fundamentales del trabajo.

Por otra parte, las soluciones apuntadas han sido objeto de críticas cuyo valor jurídico no es desdeñable. Se ha dicho al respecto que la aceptación de soluciones normativas de esta naturaleza son contraproducentes, por cuanto minimizan los derechos laborales, circunscribiéndolosa un elenco básico o elemental que desconoce las conquistas sociales de años de lucha de los trabajadores y los sindicatos, que signaron el desenvolvimiento y progreso del Derecho del Trabajo. En definitiva, ello no es más que la aceptación implícita de los postulados en los que se asientan las tendencias desreguladoras o flexibilizadoras y delos puntos devista (fundamentalmente estratégicos) de los empleadores y sus organizaciones profesionales que propug- 
nan en los últimos años una revisión de los propios Convenios I nternacionales del Trabajo aprobados en la 0.I.T., reduciendo su nómina y adaptándolos a las nuevas realidades del mundo productivo y del mercado.

Pese a estas críticas, nos pareceútil analizar al menos dos tipos de propuestas que vinculan (o que potencialmente pueden llegar a vincular desde el punto de vista jurídico) a los países de la región que están asociados en el M ERCOSUR, y que representan respuestas concretas emanadas de esta orientación. Las mismas sólo constituyen expresiones parciales de un elenco amplio de alternativas sobre regulación internacional de los derechos fundamentales del trabajo, como las más tradicionales ( $p$. ej., la ratificación de los $C$ onvenios Internacionales del Trabajo de la O .I.T.), la formulación de una carta social (p. ej., como la querigeen la U nión Europea) o los mecanismos de imposición unilateral que surgen de las prácticas constantes del comercio internacional (p.ej., el establecimiento de preferencias arancelarias, el etiquetado social, los fondos de inversión, los códigos de conducta de las empresas multinacionales).

U na primera opción se expresa a través de la aprobación de dos D eclaraciones sobre los derechos fundamentales del trabajo, que forman parte de los procesos de elaboración de instrumentos internacionales, en cierto modo considerados típicos 0 tradicionales. U na de ellas se enmarca dentro de la actividad normativa de la O .I.T. y la otra dentro de la dimensión del espacio social del MERCO SUR.

La segunda se refiere a la alternativa de las cláusulas sociales, como mecanismo abarcado por las reglas multilaterales de la O rganización Mundial del Comercio $(\mathrm{O} \mathrm{MC})$, y que pueden constituir objeto de su incorporación en la negociación de acuerdos comerciales bilaterales o multilaterales entre el M ERC O SU R y otros Estados, o con otros bloques regionales.

\section{Declaraciones sobre los derechos fundamentales del trabajo}

\subsection{La Declaración de Principios de la OIT de 1998 y su seguimiento}

Una de los pasos de mayor significación se verificó en el seno de la 0 .I.T., cuando surgiera una idea-fuerza acerca de la necesidad (para algunos) o conveniencia (para otros), de consolidar ciertos principios y derechos fundamentales sobre el trabajo, como un producto institucional. En realidad, dicha percepción involucraba algo másqueun simpleenunciado de principiosy derechos, porque lo quese pretendía era dotar al organismo de instrumentos adicionales, 0 al menos de reforzar la vigencia de los mecanismos existentes para que políticamente resultaran más contundentesy sistemáticos, con el fin de impulsar una mayor efectividad en su cumplimiento y contralor en el nivel de los Estados miembros. 
La valoración positiva sobre la actuación del Comité de Libertad Sindical en el campo delos derechos colectivosy deotros derechos humanosfundamentales conexos, constituyó una de las fuentes inspiradoras dela $D$ eclaración finalmente adoptada en 1998, concebida en términos conceptuales como una caja da resonancia para promover la observancia y salvaguarda de otros principiosy derechostambién considerados como fundamentales.

Las constataciones expuestas no significan que el proyecto haya recibido el apoyo de los actores queforman parte dela organización internacional desde una perspectiva coincidente, ni tampoco pretende olvidar que en el proceso para su consecución se plantearon numerosos cuestionamientos y se desenvolvieron intensas negociaciones.

En definitiva ello se debió a que uno de los ejes principales de la justificación del acometimiento emprendido por la O IT gira en torno a lo que ya manifestamos, las implicancias y consecuencias de la globalización en el mundo del trabajo, tema éste que lejos de concitar unanimidades, polariza el debate contemporáneo enfrentando concepciones, ideologías y estrategias.

Así lo asentaba el anterior Director General, M ichel H ansenne, al presentar la Memoria anual de 1997 en la 85a. Conferencia Internacional del Trabajo, bajo el rótulo de La actividad Normativa de la OIT en la era de la M undialización.

Tomando como punto de partida el reconocimiento dela interdependencia existente entrela liberalización del comercio y losobjetivos dela organización internacional, se planteaba como una aspiración de esta última colocar en paralelo al progreso social con el avance económico que la mundialización de la economía debería producir, en la medida que ese es su objetivo manifiesto.

Entendía el Director G eneral queexisten dos condiciones esencialeseindisociables para el logro de esta meta. La primera supone el reconocimiento universal de ciertos derechosfundamentales que aseguren a losinterlocutores del trabajo un acceso equitativo a tales beneficios económicos y que constituyan las reglas del juego de la mundialización en el ámbito social. La segunda implicala creación de un marco institucional apropiado en el quese apoyen los esfuerzos nacionales para que ese resultado potencialmente beneficioso se materialice en términos de progreso social.

En lo medular, la Declaración de 1998 reafirma los principios relativos a los derechos que son objeto de los convenios internacionales del trabajo y que reciben el rango de derechos fundamentales, de acuerdo con el reconocimiento que se les otorga dentro y fuera de la propia O IT. Los mismos están sustentados en un generalizado consenso que emerge de la conciencia universal de nuestro tiempo y comprenden:

a) la libertad de asociación y la libertad sindical y el reconocimiento efectivo del derecho de negociación colectiva; 
b) la eliminación de todas las formas de trabajo forzoso u obligatorio;

c) la abolición efectiva del trabajo infantil;

d) la eliminación de la discriminación en materia de empleo y ocupación.

Por otra parte, la D eclaración de 1998 se complementa con un Anexo que trata de su seguimiento y cuyo objetivo es facilitar vías materiales de promoción de los principios y derechos fundamentales y su efectividad. A través del mismo, la O IT primeramenteinvolucra su acción a través dela cooperación técnica, el asesoramiento y la asistencia institucionales a los Estados M iembros, promoviendo la ratificación y aplicación de los convenios fundamentales, asistiendo a los Estados que presentan carencias o dificultades para ratificar al gunos convenios y practicar los principios relativos a los derechos fundamentales y ayudando a generar un entorno favorable de desarrollo económico y social.

El seguimiento implica, como paso previo, la identificación de los ámbitos en los que la asistencia pueda resultar más útil respecto de los esfuerzos que deban efectuar los Estados. Con estefin, la propia D eclaración prevé que la O IT habrá de poner en juego los medios operativos y de funcionamiento y los recursos constitucionales y presupuestales de los que está dotada, movilizando recursos y apoyos externos y procurando alentar el respal do de tales esfuerzos por otras organizaciones internacionales con las que ha establecido relaciones.

En segundo término, el Anexo disponeel empleo de los mecanismos de control previstos constitucionalmente (los que no son sustituidos), aunque procurando en este caso redoblar su eficacia específica a través de dos modalidades operativas. Por una parte, se prevé un seguimiento anual respecto de los convenios fundamentales no ratificados en las cuatro áreas enunciadas en la D eclaración, sustituyendo así la práctica cuatrienal queel Consejo de Administración comenzó a aplicar desde 1995. Dicho seguimiento comprenderála producción por losgobiernos dememorias anuales sobre los cambios en su legislación o su práctica, las que deberán examinarse por el Consejo pudiendo éste designar un grupo de expertos en apoyo de la 0 ficina para identificar los puntos que merezcan en cada caso una discusión más detallada.

Por otra parte, se disponela realización de un informeglobal bajo la responsabilidad del Director G eneral, que persigue la optimización de resultados y que tratará sucesi vamente cada año una de las cuatro categorías de principios y derechos fundamentales. En el mismo se examinará la realidad y dinámica de cada categoría observada en el periodo cuatrienal anterior con una perspectiva general de la situación en todos los Estados, se evaluará la eficacia de la asistencia prestada por la organización y se establecerán prioridades para el periodo siguiente, elaborándose programas de 
acción en materia de cooperación técnica. Se prevé que el informe global sea presentado a la Conferencia Internacional como un informe del $D$ irector $G$ eneral para la discusión tripartita en la forma que aquella lo establezca.

Sin perjuicio y al margen del interés que puede despertar este debate, corresponde señalar que en el caso de la D eclaración de 1998, debe entenderse que se consolidan los principios y derechos fundamentales por ella enunciados, aún respecto de aquellos países que no hayan ratificado al guno o ninguno de los convenios internacionales que consagran normativamente los principios y derechos específicos a los que se refiere. Y ello porque desde el momento de su incorporación a la O IT, Ios M iembros aceptaron los principios y derechos enunciados en la C arta y en la D eclaración de Filadelfia y se comprometieron a efectuar los esfuerzos atinentes al logro de los objetivos dela organización internacional, en la medida de sus posibilidades y condiciones concretas.

En virtud de que aquellos principios y derechos fueron consagrados en convenios específicos (p. ej., los convenios internacionales núms. 87, 98, 29, 105, 138, 100 y 111), que incorporan un elenco de derechos y obligaciones, y que esos instrumentos han sido reconocidos como fundamentales dentro y fuera de la organización, por el sólo hecho de pertenecer a la misma, los M iembros deben asumir el compromiso de respetar, promover y hacer efectivos los principios relativos a los derechosfundamentales dela $\mathrm{D}$ eclaración (libertad de asociación y sindical, reconocimiento de la negociación colectiva, eliminación del trabajo forzoso, abolición del trabajo infantil y eliminación de la discriminación en materia de empleo y ocupación). Además, tal como se señala en la D eclaración, los M iembros deben cumplir esta obligación de buena fe y de conformidad con la Constitución de la O IT.

Esto supone una suerte de "autonomización" de la eficacia de un conjunto de principios sobre derechos fundamentales regulados por convenios internacionales específicos, respecto del acto formal de su ratificación a nivel nacional.

En definitiva, consideramos que es posible hacer ingresar este instrumento al elenco de grandes pactos y declaraciones de derechos humanos que consolidan el contenido del derecho universal de los derechos humanos.

\subsection{La Declaración Socio Laboral del Mercosur de 1998}

Este instrumento fue adoptado por los J efes de Estado de los países signatarios del Tratado de Asunción en la ciudad de Río de Janeiro en 1998, y consagra la proclamación solemne de los derechos sociales fundamentales que son reconocidos en el ámbito del MERCOSUR. 
La doctrina coincide en señalar quesi bien no setrata de una $C$ arta Social propiamente dicha (al estilo de la vigente en la Comunidad Europea), su importancia reside en el hecho de que expresa la dimensión concreta del espacio social en un acuerdo de integración económica y comercial, tal como políticamente fue impulsado en la región al momento de su creación. Su contenido comprende un conjunto de derechos expresamente recogidos en la $D$ eclaración, que se subdividen en:

a) D erechos Individuales:

- no discriminación

- promoción de la igualdad

- derechos de los trabajadores migrantes y fronterizos

- eliminación del trabajo forzoso

- edad mínima de ingreso al trabajo (infantil y de menores)

- derechos de los empleadores (de organizar y dirigir económica y técnicamente la empresa

b) Derechos Colectivos:

- derecho de libertad de asociación

- protección de la libertad sindical

- derecho de negociación colectiva

- derecho de huelga

- promoción de formas preventivas y alternativas de autocomposición de conflictos colectivos

- fomento del diálogo social

c) $O$ tros $D$ erechos:

- fomento del empleo y protección de los desempleados

- derecho a la formación profesional

- derecho a la seguridad y salud en el trabajo

- derecho a la protección en las condiciones y en el ambiente de trabajo

- derecho a la seguridad social

Por otra parte, la D eclaración regula normas respecto a su aplicación y seguimiento, a través de la constitución de una Comisión Sociolaboral regional, además de las Comisiones nacionales. Los cometidos básicos en esta materia son los de promover la aplicación de los derechos fundamentales, revisando las memorias anuales que deberán presentar los Estados miembros, así como las observaciones y consultas que se le formulen. Estas atribuciones se amplían tanto respecto de la determinación 
de criterios interpretativos, como propositivos (planes, programas de acción y recomendaciones, así como reformas de su texto).

U na de las características que adicionalmente deben señalarse respecto de la Declaración, es el hecho de que en sus Considerandos hace expresa referencia a múltiples instrumentos internacionales (como la Constitución, los Convenios, las Recomendaciones y la D eclaración de Principios y D erechos Fundamentales de la 0 .I.T., por una parte, y las declaraciones, pactos, protocolos y tratados que integran el patrimonio jurídico de la H umanidad, muchos de los cuales se refieren a los D erechos $\mathrm{H}$ umanos y los derechos laborales, por otra). A través de este mecanismo se ha entendido que el documento ha ampliado su contenido, el que pasó a ser mucho más genérico que el que corresponde a los enunciados concretos y expresos de su articulado (y cuyo elenco fue sintetizado precedentemente).

\subsection{Aspectos referidos a la naturaleza y eficacia de ambas Declaraciones}

Podría observarse que desde el punto de vista estrictamente formal, tanto la D eclaración de Principios y D erechos Fundamentales de la O . I.T., como la D eclaración Sociolaboral del M ERC O UR que han sido comentadas, no constituyen instrumentos jurídicos que impongan nuevas obligaciones a los Estados M iembros de aquellas instituciones, tema éste que plantea discusiones en el plano de la doctrina.

Con relación a las vías de incorporación o imposición de las normas internacionales al $D$ erecho interno, jurídicamente se señalan tres alternativas posibles:

a) debe entenderse que se incorporan por el procedimiento de la ratificación;

b) debeentenderseque lo integran ab initio por remisión constitucional (en aquellos sistemas que aceptan un bloque de constitucionalidad conformado por las normas constitucionales directas y aquell as a las cuales la Constitución se remite directa o indirectamente. En la región, estas normas corresponderían respectivamente a los arts. 33 de la Constitución argentina, $5^{\circ}$ ap. 2 de la brasileña, 45 de la paraguaya y 72 y 332 de la uruguaya);

c) debe entenderse que se imponen como jus cogens imperativo, de orden público internacional.

La eficacia, por otra parte, dependería de la naturaleza del instrumento (fuente) internacional y del tipo de cláusula (autoejecutable o programática).

D eesemodo, las D eclaraciones comentadas, podrían resultar exigibles aún cuando no supongan una ratificación expresa - tal como ocurre respecto de los convenios internacionales - por remisión constitucional o por prevalencia del derecho interna- 
cional (arts. 26 y 27 de la Convención de Viena) y/o por aplicación del "jus cogens", es decir, del cuerpo de derechos humanos básicos que constituyen el orden público internacional, más allá de cualquier acto de reconocimiento, ratificación o recepción por los ordenamientos jurídicos nacionales. (Ermida U riarte 2001).

\section{Reglas multilaterales sobre cláusulas sociales}

La segunda alternativa trata de las cláusulas sociales como mecanismos específicos que la propia O M C ha incorporado entre las reglas multilaterales e implica la posibilidad deincorporar previsiones sobre derechos laborales en las relaciones comerciales internacionales.

Generalmente se expresan en Anexos que pueden ser incluidos en tratados, convenios o acuerdos de carácter comercial, cel ebrados en forma bilateral o multilateral entre Estados o con bloques regionales. Su contenido presupone la existencia de un compromiso vinculado con el respecto o cumplimiento de determinados derechos sociales (generalmente mínimos), sometiéndose las partes obligadas a la aplicación de sanciones legales en caso de su incumplimiento (p. ej., por no respetarse tales derechos sociales). Estas penas pueden tener natural eza dineraria (p. ej., el pago de una multa) o estrictamente sancionatoria ( $p$. ej., la suspensión de las exportaciones, el cese de las ventajas reconocidas recíprocamente en sus transacciones 0 acordadas a favor de terceros países o la rescisión del acuerdo).

La experiencia enseña que han sido los países desarrollados los que proponen este tipo de regulaciones como mecanismos atemperadores de un posible "dumping social", aunque persigan loables fines de protección de derechos humanos fundamentales.

En general, estas prácticas han sido objeto de críticas por parte de los países subdesarrollados queven en ellas un mecanismo deproteccionismo indirecto en lastransacciones comerciales internacionales, impuestas por quienes poseen mayor poderío económico, capaces incluso de afectar la competitividad de sus productos de exportación por representar una elevación del costo laboral como países proveedores.

\section{Reflexiones finales}

1. Los resultados de numerosas realidades comparadas, indican que no todos los costos de las transformaciones económicas y comerciales que derivan del nuevo orden internacional, en donde globalización y flexibilización de los derechos sociales aparecen como axiomas indisociables, deben recaer sobre los factores del trabajo, especialmente si con ello se acelera una expulsión desmesurada de la mano de obra ocupada, si se alimenta el crecimiento de los bolsones de pobreza y exclusión social, 
se estimula la desestructuración del sector formal de la economía y se conculcan los derechos de ciudadanía sobre los que se asienta la democracia.

2. En el plano empírico, muchas investigaciones destacan la ausencia de una teoría económica convincente, capaz de demostrar una relación causal indiscutida entre flexibilidad del mercado de trabajo y un importante descenso del desempleo 0 un aumento de la inversión, tal como lo han demostrado el Informe Dahrendorf sobre la realidad europea (1986) y las formulaciones que efectuaran SARFATI y KO BRIN sobrela flexibilización del mercado de trabajo (1988).

Ello se debe a que la flexibilidad laboral no constituye la panacea de todos los males económicos, ya que las medidas desregulatorias de la normativa del trabajo y el abatimiento de los costos laborales y sociales resultan secundarias y de un peso relativo frente a otros factores de corte netamente económico y comercial, como entre otros - los déficits de la hacienda pública, los desequilibrios en las balanzas de pagos, los intereses de la deuda, las dificultades de los mercados de financiación y las cargas tributarias.

3. Por otra parte, parece claro que resultarían muy altos los costos políticos que deberían enfrentar los gobiernos si se encamiran acciones desprotectoras extremas, y las experiencias institucionales vividas en el pasado cercano en toda la región, obliga a resguardar la estabilidad democrática de los Estados.

4. Existen asimismo límites jurídicos a las experiencias desreguladoras, muchos de los cuales encuentran su fuenteen precisas disposiciones internacionales. La carta dela OIT partedel principio analizado dequeel trabajo no debe ser considerado como una mercancía, quela competencia internacional no debería basarse en el costo del trabajo y que las malas condiciones de trabajo atentan contra la paz mundial. La nómina podría ampliarse, mencionándose innúmeras disposiciones de Convenios Internacionales del Trabajo, D eclaraciones, Tratados y Pactos internacionales y regionales vigentes en los distintos países (Barbagelata 1989: 414 y sigs.).

Tanto la D eclaración de Principios y su seguimiento de la O IT, como la D eclaración Sociolaboral del M ercosur, constituyen instrumentos internacionales de primer orden para los países de la región.

5. Tal como lo ha definido un recordado fallo dela C orteSuprema en Argentina, la justicia social traduce un concepto de justicia por medio dela cual seconsigue o se tiende a alcanzar el bienestar. Ello implica, según se ha señalado, que las normas deben ser interpretadas a favor de quienes, al serles aplicadas con ese sentido, tienden o consiguen al canzar «las condiciones de vida mediante las cuales es posible a la persona humana desarrollarse conforme a su excelsa dignidad» (Bercaitz, M iguel Angel s/jubilación, 13/9/74). 
Por tanto, libertad, dignidad y justicia social, son valores que están ínsitos en los derechos fundamentales, debiendo ser observados en las legislaciones y en las prácticas laborales, no sólo como enunciados programáticos, sino como ordenadores sustentables de las políticas económicas y sociales.

6. A partir del reconocimiento de quela ciudadanía no consiste simplemente en la pertenencia a un determinado Estado, generando derechos y obligaciones políticas, ha ido plasmándose un concepto de la misma que comprende una proyección laboral y social más amplia. Por la primera, ha de reconocérsele al trabajador su derecho a participar, individual y colectivamente, en todas las manifestaciones del trabajo, y por la segunda, a gozar y ejercer sus derechos fundamentales que, como persona, le resultan inherentes a su condición humana.

D e allí que la preservación real de la democracia requiere su extensión a nivel internacional y la de la ciudadanía social requiere una re-regulación internacional (Ermida Uriarte 2003).

D eallí la importancia de queel nuevo orden económico y comercial globalizados, promuevan el desarrollo de una dimensión social de las naciones, especialmente de aquellas que carecen de suficiente desenvolvimiento.

Ello debería viabilizarse a través de compromisos internacionales equitativos, que permitan el acceso de los países al mercado internacional, a la tecnología y a la radicación de inversiones. Para lograrlo se torna necesario proyectar una articulación entre las políticas económicas y sociales, por medio de programas eficientes capaces de garantizar a las personas el derecho a trabajar y generar un ingreso digno, acceder a servicios de salud, vivienda, educación, formación profesional y seguridad social,

Sólo de esa forma se podrá sal vaguardar la vigencia de una democracia sustantiva plena y la posibilidad de un ejercicio real y efectivo de los derechos de ciudadanía, como expresión de los derechos fundamentales que constituyen su esencia.

\section{Referências Bibliográficas}

ALO N SO O LEA, M. I Jornadas U niversitarias Andaluzas de D erecho del Trabajo. Córdoba, España, 1983.

AA.VV. "As políticas macroeconômicas e o perfil dos países do M ercosul: entraves à integracao", In: América Latina e Caribe e os D esafíos da N ova O rdem M undial, vol. II, São Paulo, V Solar, 1996.

BARBAG ELATA, H .-H . El particulari mo del D erecho del Trabajo. $1^{\text {a }}$ ed. M ontevideo, FCU , 1985.

BARBAGELATA, H .-H . "Los límites dela flexibilidad del mercado de trabajo", In: Revista D erecho Laboral, tomo XXXII, M ontevideo, 1989. 
BELZU N EGU I ERASO, A. Teletrabajo: estrategias deflexibilidad. M adrid, ed. CES, 2002.

BONETTO, M. S. y PIÑERO, M.T. El discurso sobre el trabajo en Argentina, en Costos sociales de las reformas neoliberales en América Latina. Caracas, Pontifica Universidad C atólica de São Paulo, 2000.

CACCIAM ALI, M.C. "Liberalización económica y derechos fundamentales en el trabajo en América Latina". In: Los desafíos de la política social en América Latina. Caracas, 2002.

ERMIDA URIARTE, O. "Aplicación judicial de normas constitucionales e internacionales" In: XIII Jornadas U ruguayas de Derecho del Trabajo y de la Seguridad Social. La Paloma, 2001.

ERM IDA URIARTE, O. La dimensión social del Mercosur. Montevideo, Ed. mimeográfica, 2003.

GRANDI, M. "El trabajo no es una mercancía”. In: Evolución del Pensamiento Juslaboralista. M ontevideo, Ed. FCU, 1997.

Informe D AH REN D O RF. O CDE. Paris, 1986.

O .I.T. Globalización y trabajo decente en lasAméricas. XV Reunión Regional Americana, Lima, 2002.

0 .I.T. "La actividad N ormativa dela O IT en la era de la M undialización", M emoria anual de la 85a. C onferencia Internacional del Trabajo, Ginebra, 1997.

RO SEN BAU M , J. “EI debate contemporáneo sobre reglamentación y desregulación del Derecho del Trabajo". In: Rev. RELASU R, núm. 8. M ontevideo, OIT, 1995.

SARFATI y KOBRIN. Antología comparada sobre la flexibilización del mercado de trabajo. M adrid, Colección Informes de la O .I.T., 1988.

TOFLER, A. La empresa flexible. Barcelona, Ed. Plaza \& Janés, 1990. 
Jorge Rosenbaum Rimolo - Cadernos PRO LAM /U SP (ano 2 - vol. 2 - 2003), p. 25-43 